\title{
Lipid characteristics in cooked, chill-reheated fillets of Indo-Pacific king mackerel (Scomberomorous guttatus).
}

\begin{abstract}
Slices of Scomberomorous guttatus cooked by four different methods (microwave cooking, grilling, steaming and shallow fat frying) were kept chilled at $5{ }^{\circ} \mathrm{C}$ for 2 days, reheated by microwave and then evaluated for the changes in the lipid characteristics. The total lipid content for raw sample was $6.0 \mathrm{~g} / 100 \mathrm{~g}$ which consist of $49.4 \mathrm{~g} / 100 \mathrm{~g}$ saturated (SFA), 6.9 $\mathrm{g} / 100 \mathrm{~g}$ monounsaturated (MUFA) and $43.8 \mathrm{~g} / 100 \mathrm{~g}$ polyunsaturated fatty acids (PUFA). Upon cooking, the total lipids changed to about 7 (microwave), 11 (grilling), 5 (steaming) and $10 \mathrm{~g} / 100 \mathrm{~g}$ (shallow fat frying). These changes are significant, with the exception of steam cooking. Cooking did not significantly affect the percentage of NPL, PL, SFA, MUFA and PUFA in the samples. Frying resulted in the change of the SFA/PUFA ratio more than other cooking methods. A significant $(\mathrm{P}<0.05)$ decrease in the content of EPA was only found in the fried samples. A significant $(\mathrm{P}<0.05)$ decrease in the content of DHA in all cooked samples were also obtained. The n-6/n-3 ratio did not change significantly in all cooked and reheated samples, except for shallow fat fried. Reheating did not significantly affect the NPL and PL contents of the fillets, except for microwave cooked samples. Cooking increases the FFA, PV and TBA of samples; reheating enhances the increase.
\end{abstract}

Keyword: Scromberous guttatus; DHA; EPA; Fatty acid profiles. 